\title{
Research on Elastic Design of Modern Office Space Based on Ecological Theory
}

Peng Gu ${ }^{1,2}$

\author{
${ }^{1}$ School of Art and Design, Wuhan University of Technology, Wuhan 430070, China \\ ${ }^{2}$ Shandong University of Arts, Jinan 250014, China \\ gp-6978@163.com
}

\section{Keywords: Elastic Design; Office space; Sustainable Development}

\begin{abstract}
The design of office space lacks consideration of humanization and sustainability, and there are problems such as static design concept. The versatility of the space is not suitable for the development of society. This paper first explains the concept of elasticity in ecology, briefly reviews the development process of office space elastic design theory, and then, through the development process of analysis, summarizes the general principles and specific methods of elastic design in office space. Introducing "elastic design" in the office space, making it free to change and combine with people's needs is an effective way to solve this problem. "Flexible Design" can be designed to create a versatile space that allows people to work and rest, communicate with others, and meet the potential for future work. The design of office space should be truly people-oriented, break the traditional design thinking and achieve sustainable development of space.
\end{abstract}

\section{The Concept of Elasticity in Ecology}

In ecology, elasticity refers to the ability of a society to recover its basic structure and function after being disturbed. Eco-elasticity acts on the social-ecosystem and is an alternative way to "understand the world around and manage natural resources". [1] Through the two concepts of depreciation and adaptive cycling, the impact of human social behavior on the environment is constrained, and environmental degradation caused by social development is reduced.

The concept of elasticity is widely applicable, and it can be generalized to obtain the following characteristics: Elasticity describes the relationship between two variables in the system, and these two variables have a causal relationship. Elasticity can be abstracted as a property of one variable in a system that changes with another. Elasticity can be expressed as sensitivity or adaptability under certain conditions, that is, the degree of response of the independent variable under the same increment or decrement of the dependent variable. The key to studying the elasticity of the system is to identify two variables with causality and to clarify the characteristics of the changes between them.[1]

Canadian ecologist Holfing first proposed the concept of ecosystem resilience in his paper "Resilience and stability of ecological systems" in 1973.[2] Elasticity is the property of the system, while the probability of persistence or extinction is the result. Then the Resilience Alliance expands the elasticity into an important concept for expressing the adaptive capacity of the socio-ecological system. Elasticity applies to ecosystems or integrated systems of people and natural resources. The elasticity of social-ecological systems is ecological. The key to economic and social sustainability. A resilient system can withstand the total amount of change and still maintain its original function and structure, can be self-organized, and can build and enhance learning and adaptability. Adaptability is a component of elasticity and a system behavior that responds to interference. In the practical application of the flexible concept, it is necessary to clarify when and where management intervention can prevent the bad change of the system's adaptive ability. The measurement elasticity often needs to be defined by empiricity and context. 


\section{Development of Office Space Design}

Development history of office space in the industrial age

In the 1860s, the emergence of steam technology represented the emergence of the industrial revolution, thus opening a new chapter in the history of human development.[2] The pursuit of efficiency and economy in this industrial revolution has completely changed the overall appearance of the office space and the way people work in the office space. The real office building and office space will follow. The social production of any era is aimed at pursuing efficiency and economy. Office buildings and their interior spaces are also transforming around this theme. Therefore, according to the dynamic development of office space in the industrial era, it can be divided into three main stages: open factory office space, landscape office space and electrified office space.

The emergence of large space and factory office space

After the industrial revolution, people gradually stepped out of the countryside and entered cities and towns, and walked into the office from the family. The collective office followed, and the real office space began to emerge. Prior to this, the office space was mainly based on the reading room of the church clergy and the office of the government agency, and the personal office space was used for planning and arrangement, and the social class and hierarchy were extremely obvious. In the middle and late 19th century, with the increase of the benefits of commercial activities, the invention of office equipment such as telegraphs, typewriters, and telephones accelerated the communication between customers, suppliers and peers and trading partners, and large capital-concentrated enterprises appeared one after another.

Appearance of landscape and electrified office space

Due to the profound influence of Taylor's "scientific management" theory, office work is subdivided into individual tasks, management standardization to maximize efficiency, and the primary purpose of office environment creation is thus determined: logical and rational. With the advent of high-rise office buildings with glass curtain walls and the use of air conditioners in the 1930s and fluorescent lamps in the 1940s, the depth of these glass-box office buildings was limited by day lighting and natural ventilation, creating a large office space. [3] At this time, the idea of landscape office appeared. It is a reflection on the simple and rational concept of the office space of early modernism, and it is a kind of detachment from neglecting interpersonal communication.

The form of landscape office space caused by the economic recession of the 1970s was gradually abandoned. This change was caused by the economic recession caused by the oil crisis of 1973. At the same time, the increase in indoor lighting and heating costs made the company's advantages in the 1960s expensive. In addition, the landscape office space was poor due to natural lighting. Lack of outdoor visibility, natural ventilation, and lack of personal privacy make landscaped office buildings less popular.

Systematic, diversified office space in the information age

The "post-industrial society", also known as the "information society", is a generalization of the nature of society after Western industrialists and sociologists follow the industrial society. Since the 1990s, the main growth point of the world economy has been two knowledge-based industries, communication and information. Digitalization, networking, and virtualization have become the main features of the new economy. The degree of office automation is constantly deepening, and new office methods are constantly emerging. The traditional pyramid structure and organizational form of the enterprise have gradually developed into a flat, and the professional project team cooperation team has gradually become a new office mode.[3] The type of office space has gradually got rid of the single form and function, and the trend toward virtual office space has developed rapidly. The mobility brought about by miniaturized computers and phones has changed the way people manage global businesses in whole and in part. At the same time, information technology has also rapidly changed the concept of corporate organization and work. 


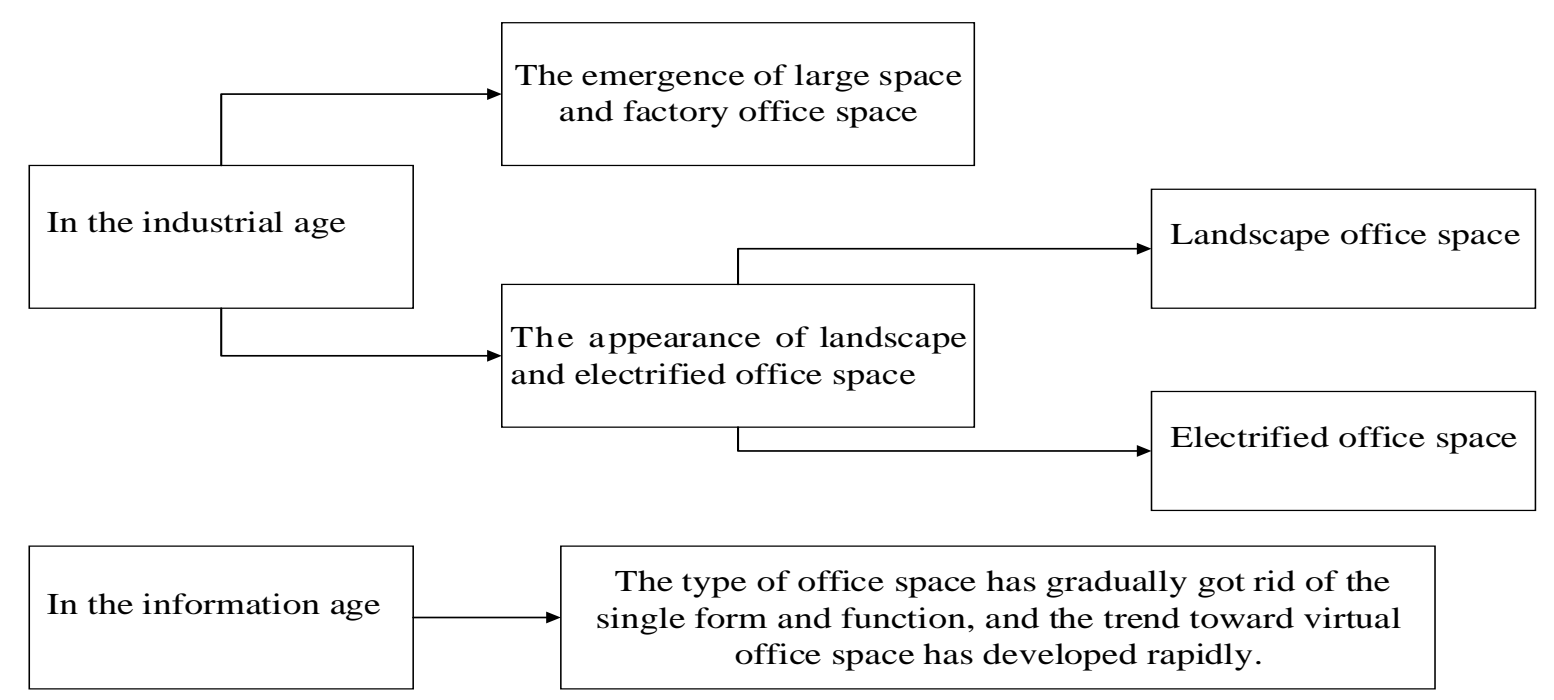

Figure1. Overall development of office space design

\section{Problems in the Design of Office Space at the Present Stage}

Excessive pursuit of high utilization, air quality decline

Although the design of office space is constantly meeting people's higher requirements and expectations, there are still many problems in contemporary office space that need to be solved. The most prominent problem is that some enterprises have excessively increased the use density of office space in order to excessively pursue space utilization, and arranged as many desks and chairs as possible in a limited area, resulting in overcrowding of the use space.[3]

The use of modern office equipment, radiation, noise pollution is serious

More and more office equipment in the office space brings work efficiency to the office staff on the one hand, and affects the user's health on the other hand. The process of electric and magnetic field propagation is called electromagnetic radiation. This invisible and inexhaustible electromagnetic radiation is invading every corner of the office silently.

Space environment lacks personality, ignoring the user's psychological feelings

Office design should pay attention to space communication and contact. The unreasonable design of the traffic flow line in the space and the rigid form of the space also affect the user's work efficiency and mood. There are still a lot of office space not completely rid of the traditional space form, lack of opportunities for communication between employees, neglecting the use. Behavior patterns and diversity of office space. In addition to some office space and meeting rooms, there is no space and facilities for employees to enjoy entertainment. The office space is relatively simple, ignoring the comfort and spiritual life of people at work. Many of the design of office space are similar in form, and they are monotonous and lack individuality.

\section{The Significance of the Flexible Design of Modern Office Space}

Meet the needs of sustainable development of the building

The flexible design concept is the concrete embodiment of the sustainable development idea in the interior design. The adjustability and variability of the spatial function advocated by it is the basic guarantee for implementing the sustainable development of the building. At the same time, many of the design principles embodied in sustainable development are also applied to elastic design, such as durable design, reusable design, and increased use of renewable energy.[4]

Facilitate the transformation and reuse of buildings

Buildings can also be regarded as living organisms. The old buildings can continue to revitalize in the continuous interpretation of modern society. Many successful cases of old building renovation have greatly extended the life of the building, and also reflected the inheritance and continuation of its cultural value. In the process of retrofitting old buildings, there is a problem of 
new requirements and old ones, new technologies and old models. Introducing a flexible design concept requires designers to consider these issues at the beginning of the design. Make sure that after the building has been in use for a period of time, it can also be retrofitted according to changes in demand. This is also the standard for testing the success of elastic design.

Ability to resolve specific contradictions within a specific period and within a specific scope

There are certain contradictions and conflicts between the certainty of buildings and the diversity and immediacy of human activities. Such contradictions and conflicts are called unpredictable factors of architectural design. Elastic design proposes a more effective method for this unmeasurable factor.[4] Although it cannot exhaust all possibilities, it can properly resolve the contradiction between the certainty of the building and the future demand changes.

The changing conditions of buildings and the full use of potential conditions should be important criteria for judging

In today's society, the adaptability of architectural space is often overlooked by people. Whether it is users or designers or investors, they are more concerned with the practical functions, artistic style, strong visual impact and so on of a certain space. Therefore, the current space gradually develops into a new and different aesthetic direction with strong visual impact. This short-sighted behavior eventually forms the most eye-catching "signature space", and the adaptive ability of functions is gradually neglected. In the past assessment of spatial value, people usually only see the immediate interests, resulting in waste of resources and environmental pollution. Therefore, the quality of a space is not determined by the short-sighted behavior of such resources, but depends on whether the space has strong adaptability.

\section{Research on the Flexible Design Strategy of Office Space}

Words such as speed, variability, and diversification are ubiquitous in all areas of the current society, and in this environment, office space design has become increasingly complex. The following is a summary of the specific methods of elastic design in office space from three aspects: planning design, construction and functional expansion. The specific process can be seen in figure 2 .

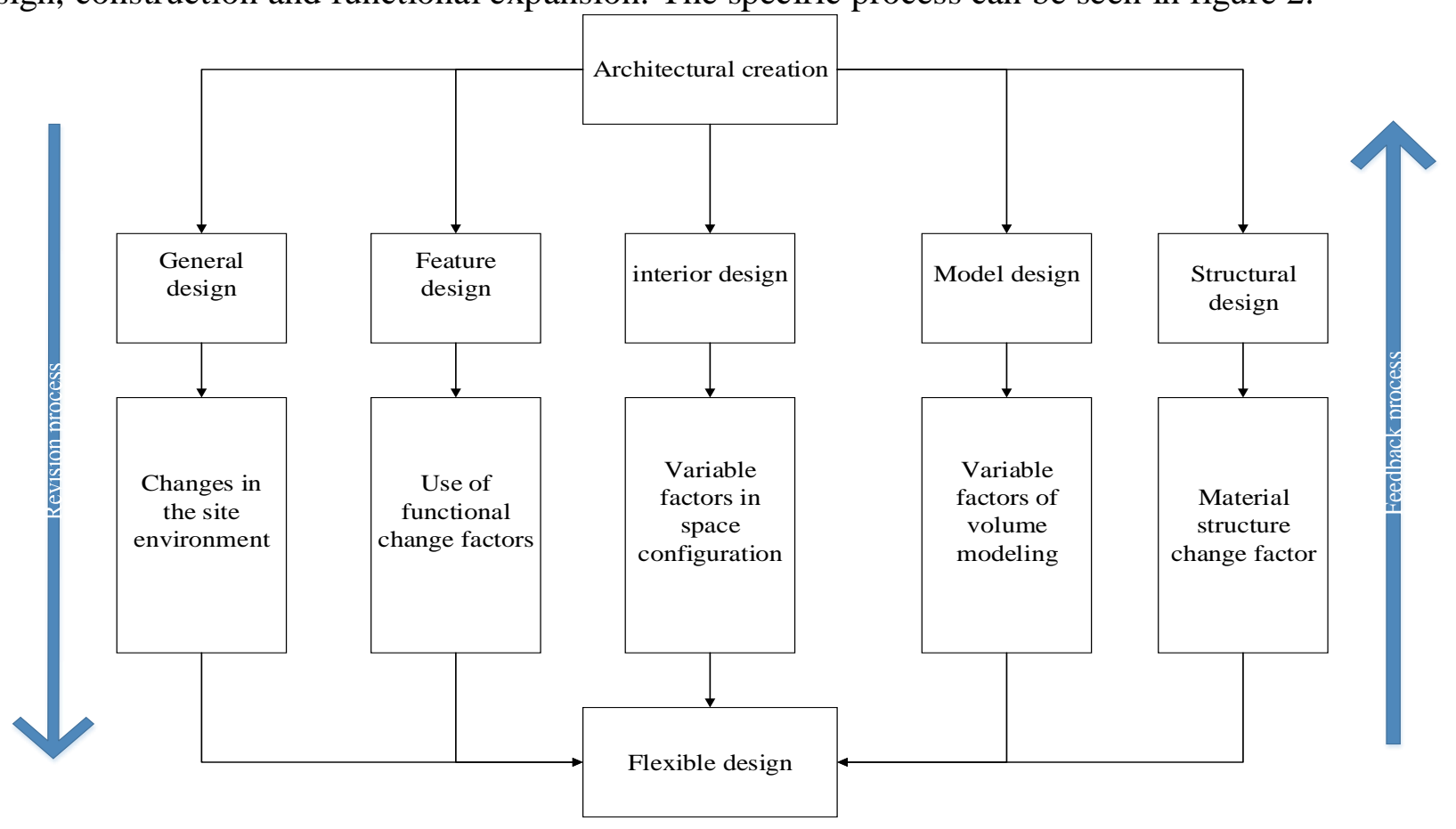

Figure 2 Specific method of elastic design

Spatial modularization method

The modular design is based on a certain modulus of opening, depth, layer height and load, and the "modulo space unit" designed, constructed and assembled according to the modulus is the basic 
unit. This is designed according to the "three unified" modulus. The spatial units are combined in an array to form a large indoor space.

Method of distinguishing fixed body from variable body

A fixed body in an office space refers to a fixed shaped part constructed by a standardized production method. In the office space of a bank's Jinan branch, the implementation of the "table" system (when the office area is small, there is something to do, and the matter goes away) not only reduces the pressure on the small office area and the shortage of the work station, but also works in it. The staff is no longer confined to their own small world, greatly enhancing their chances of standing out. The combination of fixed body and variable body in office space not only solves the contradiction between standardization and diversification, but also provides convenience for space flexibility.

Method of material and component replaceability

The materials and components used in the space are designed to be flexible and adaptable due to various factors after a period of use. The Bergen International Festival Office is a company that plans festival events, and every day there are some projects added. In order to ensure the increasing number of active project operations and the number of employees per year, as well as the multiple possibilities of office activities, the freedom to adjust spatial functions is required to be high. Eriksen Skajaa Architects uses a wood frame grid to define the language of this space, showing the unfinished state of nature. The assembled wood frame structure facilitates flexible adjustment of the space, and the disassembled components can be reused, saving resources.

\section{Conclusions}

The attention is often paid to the functional space currently required by the building's exterior and office space, but the change in working mode. Driven by the sustainable development strategy, the flexible design in the office space has been paid more and more attention, and there is still a broad space for development. The success of flexible office space design is not just the use of any one or more of the above mentioned methods, which means that space is given flexibility. The convenience, comfort, leadership management and so on of employees using this space are decisive. factor. In addition, whether to use the elastic design method should also consider this office space in the overall building. If the influence of other factors is neglected in the process of pursuing the flexibility of space, it may not be able to make a real flexible office space. . As a designer, we should stand in the perspective of employees and shoulder the corresponding sense of social responsibility. Under the guidance of the flexible design theory, we should care for the working people in terms of physical and psychological aspects, and create a variable spatial form, no matter how time changes, let People's physical and psychological needs can be supported and coordinated by the material space. It is hoped that through the research of this subject, we will explore the high practical value of flexible design in office space, break the traditional design thinking, carry out design concept innovation, pursue humanized design of space, and achieve space sustainability.

\section{References}

[1] Li, Qi Bing, and Y. Huang. "Research on Dynamic Balance of Linkage Considering the Influence of Elastic Deformation Based on Simulation." Applied Mechanics \& Materials,2012(12):1465+1470.

[2] Lin, Shao Jian, et al. "Research on Low Temperature Elastic Recovery Property of a Novel Poly(ester-Imide-Ether) Based on N-(4-Carboxyphenyl) Trimellitimide Unit." Advanced Materials Research,2012(10):122+125.

[3] Shu, Zu Ju, S. Q. Liu, and Y. Yuan. "Research on Elastic Modulus of Wooden Crates for Simulation." Applied Mechanics \& Materials, 2012(200):528+531.

[4] Liu, Yi Ling, and S. Q. Li. "Empirical Research on Ecological Carrying Capacity Evaluation of Agricultural Industrialization Leading Enterprises." Advanced Materials

Research ,2014(1):717+721. 